\title{
Integrating Information from Multiple Methods into the Analysis of Perceived Risk of Crime: The Role of Geo-Referenced Field Data and Mobile Methods
}

\author{
Jane Fielding and Nigel Fielding \\ Department of Sociology, University of Surrey, Guildford, Surrey GU2 7XH, UK \\ Correspondence should be addressed to Jane Fielding; j.fielding@surrey.ac.uk
}

Received 26 June 2013; Accepted 12 November 2013

Academic Editor: Augustine Joseph Kposowa

Copyright (C) 2013 J. Fielding and N. Fielding. This is an open access article distributed under the Creative Commons Attribution License, which permits unrestricted use, distribution, and reproduction in any medium, provided the original work is properly cited.

\begin{abstract}
This paper demonstrates the use of mixed methods discovery techniques to explore public perceptions of community safety and risk, using computational techniques that combine and integrate layers of information to reveal connections between community and place. Perceived vulnerability to crime is conceptualised using an etic/emic framework. The etic "outsider" viewpoint imposes its categorisation of vulnerability not only on areas ("crime hot spots" or "deprived neighbourhoods") but also on socially constructed groupings of individuals (the "sick" or the "poor") based on particular qualities considered relevant by the analyst. The range of qualities is often both narrow and shallow. The alternative, emic, "insider" perspective explores vulnerability based on the meanings held by the individuals informed by their lived experience. Using recorded crime data and Census-derived area classifications, we categorise an area in Southern England from an etic viewpoint. Mobile interviews with local residents and police community support officers and researcher-led environmental audits provide qualitative emic data. GIS software provides spatial context to analytically link both quantitative and qualitative data. We demonstrate how this approach reveals hidden sources of community resilience and produces findings that explicate low level social disorder and vandalism as turns in a "dialogue" of resistance against urbanisation and property development.
\end{abstract}

\section{Introduction}

This paper demonstrates the use of computationally based mixed methods discovery techniques to enhance the power and analytical reach of fieldwork in the study of crime risk and public safety. The substantive focus of this paper is on community safety and the perception of risk from crime and social disorder at neighbourhood level. Our conceptual focus is on the application of an etic/emic framework for vulnerability to crime. Our methodological focus is on a mixed methods approach using software to help combine and integrate layers of information to reveal connections between community, crime, and place. This demonstrator study draws on primary empirical data from fieldwork at sites and in criminal justice settings in a contemporary English town.

In countries like the US and the UK the policy register for research on safety and risk is "community policing."
Police forces and police researchers in such countries have developed the diagnostic activity of the "environmental scan" as a tool to gauge public risk perception in so far as it relates to the built environment. The present official system for community policing in England and Wales is labelled "Neighbourhood Policing." Neighbourhood policing includes the practice of the environmental scan alongside community consultation and crime audits. Our research seeks to extend environmental scan methodologies by new procedures and IT tools. However, we also have a conceptual or analytic objective.

In our analysis, procedures like the environmental scan are one-way practices that presume that the police and State are always benign and that the noncriminal public always stand beside them. We are interested in developing a richer conceptual frame that recognises not only the unintended criminogenic consequences of official interventions but also 
the social pathologies driven by competing interest groups against a backcloth of general public indifference in communities where crime and disorder are a relatively modest part of everyday life. We are not arguing that the public are indifferent to crime and social disorder but that public sentiment is intermittent, being mobilised largely by the reporting of high profile crimes or when personally touched by crime as a victim or when victims are in one's proximal social network [1]. To this we add that when crime and disorder do become a concern it is too little recognised that individuals, families, and small friendship networks have their own resources that may make them resilient in ways that are barely detectable by formal agencies and agents of criminal justice.

The field of community safety and risk perception has been dominated by an understandable but empirically questionable assumption that crime and disorder are major stressors and concerns for the general public. These assumptions may be an artefact of the survey methods that are the principal source of our understanding of crime fear. Within an international context of steadily falling crime rates, England and Wales are themselves relatively low crime countries. To better direct our limited resources of crime prevention, public reassurance, and crime detection to areas where there is a real need, we must get to better know our communities. Such an agenda applies to recent interventions based on "participatory appraisal," where policy is informed by research that involves community participants mapping points of importance to them (see Fielding and CisnerosPuebla [2] as an example). Our headline research question is therefore "what is the basis of resilience against crime and disorder in a stable neighbourhood located at the median in standard indices of deprivation/prosperity?" The technologically enhanced fieldwork methods we demonstrate here produce results that we see as useful comparators to data from the British Crime Survey (since April 2012 known as the Crime Survey for England and Wales) and other large sample surveys on the distribution of victimisation and its effects.

\section{Applying the Emic/Etic Distinction to Perceptions of Risk and Safety in a Community}

A useful framework for exploring these ideas of risk and safety in the community is that of an emic and etic conceptualisation of vulnerability [3, 4]. These concepts, re-interpreted from linguistics and anthropology, refer to two complementary perspectives.

An etic perspective defines risk from an "outsiders" viewpoint, thus imposing the vulnerable categorisation not only on areas (such as "crime hot spots" or "deprived neighbourhoods") but also on groupings of individuals, often based on their assumed dependency (such as the "sick" and the "poor"). The groupings are generally underpinned by relative position in respect of a limited range of sociodemographic indicators, drawn together around a broad, monochrome label. The alternative, emic, perspective explores vulnerability based on the meanings held by the individuals informed by their lived experience and expressed in their own terms. Individuals classified as "vulnerable" from an etic perspective may not feel vulnerable from a personal, emic, perspective. Thus both viewpoints are needed to fully explore social phenomena such as risk and vulnerability.

An approach combining both perspectives necessarily involves a mixed methods research design. In the case of our research, police-recorded crime data and area classifications derived from Census data are used to categorise a local area from an etic viewpoint, emulating a standard approach to inference from population characteristics. Mobile interviews with local residents and police community support officers (PCSOs) and researcher-led environmental audits, conducted while being on accompanied walks around the area discussing and recording visible risk/reassurance indicators, provide additional layers of data from an emic viewpoint. To handle such a variety of data types, several software tools were needed as profiled in Figure 1.

Figure 1 displays the interrelationships between the data, the technology, and the software tools for both data collection in the field and analysis, and exemplar output from using such tools. Audio data were collected using digital recorders (Olympus DS-40), and GPS tracks were either captured using a smart phone (a Sony Ericsson Xperia X1) running Garmin Mobile XT or a handheld GPS device (Garmin eTrex). Quantitative survey data (and still images) were captured using the smart phone and SurveyToGo software [5]. Data representing the etic viewpoint were analysed using statistical software (IBM-SPSS), the emic viewpoint was explored with qualitative software (ATLAS-ti [6] and MAXQDA [7]), and geographical context was analytically linked to the quantitative and qualitative data using GIS software (ArcGIS 9.3 and Google Earth 6). The objective of integrating multiple methods and using various software tools is that data from them coalesce to produce information which is both related and linked. We choose the term "coalesce" deliberately. In a mixed methods research design, data may or may not converge. Used as a discovery technique it is important not to suppress variation or prematurely apply analytic closure. Indeed, there is an established argument in the mixed methods literature that apparently contradictory data may be particularly conceptually illuminating and we should not regard a lack of agreement between data of different kinds as a failure of method [8]. In fact, we should also explore cases where data from different elements of the research design conveniently fit together with equal stringency. These are helpful principles when our objective is "discovery," the fuller exploration of elusive or complex social phenomena.

In the present context such an exploration calls on us methodologically to address the question of the basis on which sociodemographic and crime profile data produced from secondary data can be compared with primary data based on local intelligence derived from fieldwork. Our general premise is that this requires drilling down to match as closely as possible the secondary data to the specific contextual characteristics of the primary data. Secondary and primary data should be matched as closely as possible in time, duration, and period and likewise in place and space. The temporal consideration requires us to align the time at which 


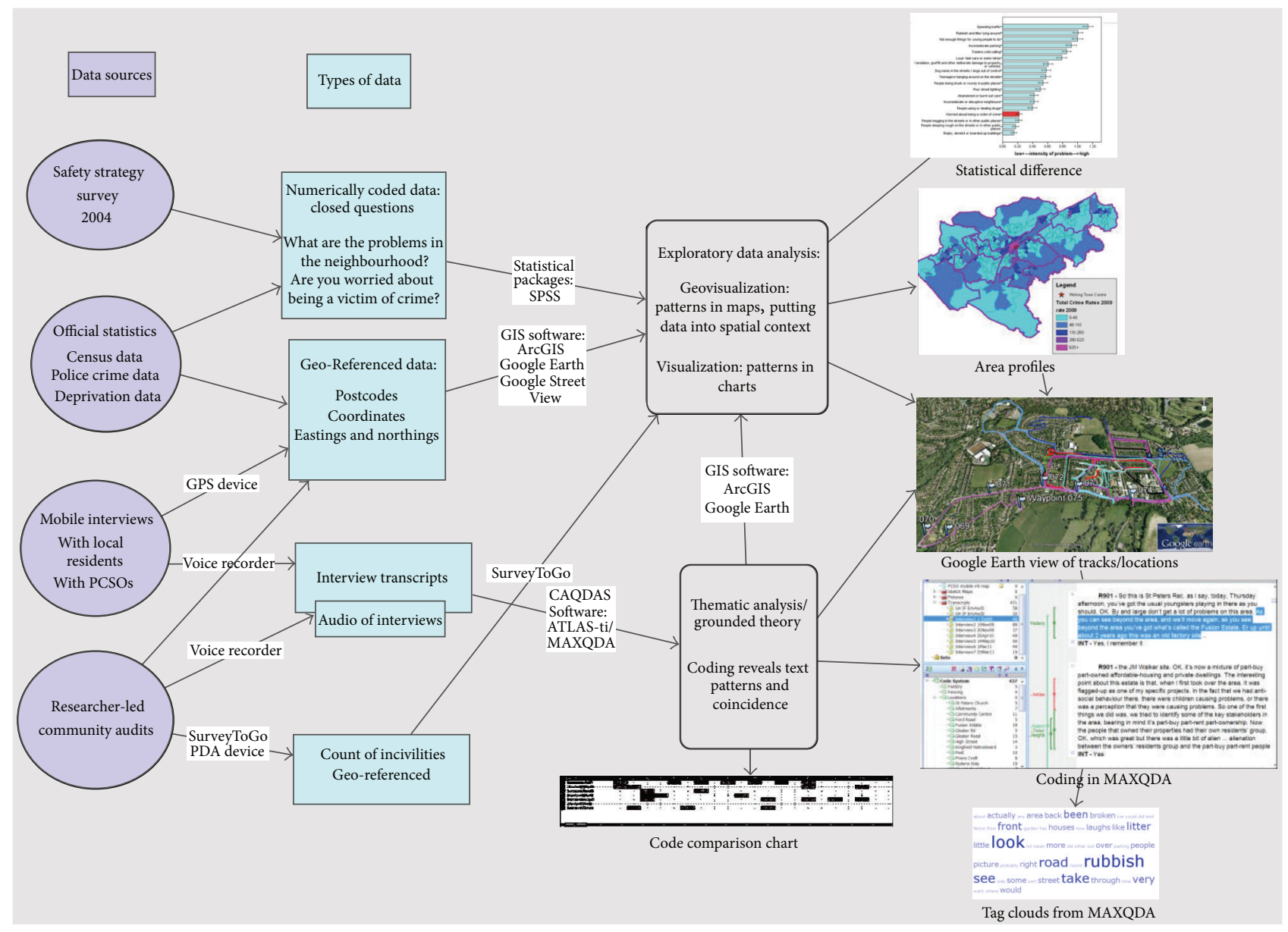

Figure 1: Data sources and technology and software tools for collection and analysis.

secondary data were drawn with that of the specific episode of data elicitation and, in respect of recall data, the time to which respondents refer and/or the time when physical artefacts in question were present (e.g., the date of closure of a factory that became derelict, affording illicit play space, and vandalism opportunities). As the factory example suggests, duration may be lengthy or ephemeral (e.g., in many jurisdictions local government commits to removing abandoned vehicles within a few working days). Period may be addressed by seeking to capture the "crisis point" at which a crime-related phenomenon is in the public eye. In terms of secondary data this can sometimes be captured by peaks in media reports and/or the drawing up and publication of special editions of official data examining a given issue in detail in response to public concern; this happened, for instance, in the mid 1980s following high profile cases of "network" sexual abuse of children [9]. As to spatial considerations, place involves matching of secondary and primary data in respect of geolocation, where Census "output area"/"block" level information is a substantial resource providing finer granularity to which sociogeographical descriptors can be attached that characterise and differentiate very small clusters of residential addresses by socioeconomic qualities assigned to a resident typology, with the most basic being social class. Space in our usage refers to the extent or "reach" of a given attribution; this is useful in sites that have "mixed" characteristics, such as a residential area comprised mostly of properties whose residents enjoy secure housing tenure but where there is a "bad end" comprising social housing with high turnover of tenancies.

As we will see, the scope for precision in matching secondary and primary data is increasing on the back of "open data" initiatives and the willingness of commercial data providers to grant access to datasets produced for other purposes, but there remain significant constraints that must be negotiated. At the broadest level, the hallmark problem of secondary data is granularity-coverage may be insufficiently "micro," or, when it is sufficiently geolocal, exact locations may be deliberately obscured to protect citizen identity or sensitive locations (e.g., military facilities). At the broadest level, the hallmark problem of primary data is the established issues of reliability (transferability to other settings) and validity (accuracy of subjective accounts of social phenomenon elicited from respondents). In both cases, these issues can be addressed by a mixed methods research design and comparative analysis, although certainty will always be bounded by the generic epistemology of interpretive social science. 


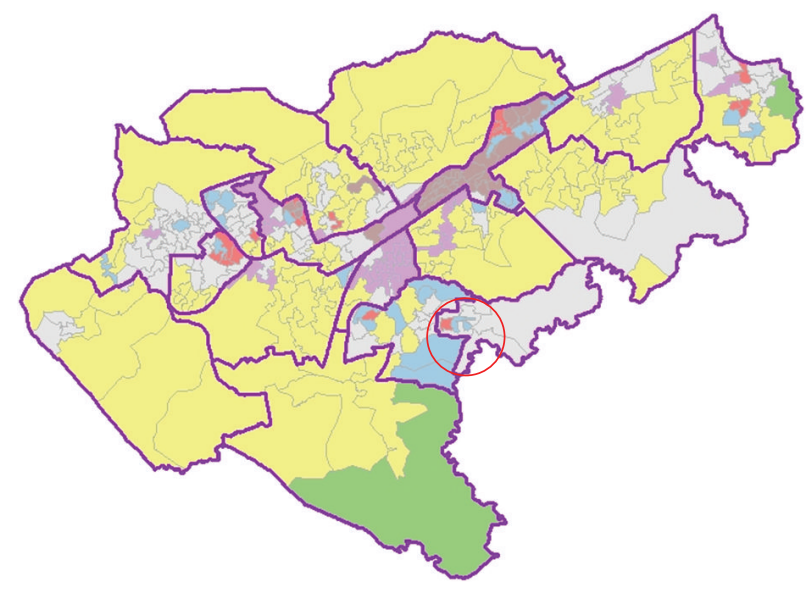

OA classifications SuperGroups SUPERGROUP Name

$\square$ (1) Blue collar communities $\square$ (5) Constrained by circumstances
(2) City living
(3) Countryside
(3) Coul traits
(4) Prospering suburbs

Figure 2: Profile of the district (granted borough status in 1974). Note: circle indicates sample area. Source: IMD 2010 [10]; ONS 2001 [11].

An important matter in a locally based study is the ethical dimension of site selection. Both fieldwork methods and georeferencing challenge the participant anonymisation convention that social researchers normally adopt. We do not attempt to disguise the location of the fieldwork site in this paper, because we believe that the data to be considered here are not especially contentious and cannot be tied to individual respondents (only the site is identified; the anonymisation convention is observed in relation to individuals quoted or discussed). But we do need to recognise that the more finegrained our methods are, the greater are the concerns over identifiability and that sophisticated technology has a role in this. Its affordances include means by which anonymity can more readily be penetrated, and consideration of technical protections is an important part of proceeding ethically.

\section{Methodology}

3.1. Profile of the Research Community. The research site discussed in this paper was chosen as an instance of a mixed residential community with population and tenure stability that nevertheless had a historically problematic reputation and was "socially deprived" in the context of this area. Figure 2 shows a map of the research district, displaying the supergroup Output Area Classifications (OAC), which are based on the UK 2001 Census data. The $k$-mean clustering methods used to create these seven supergroup OACs, and derivation and conventions used to name the supergroup classifications are described in detail by Vickers and Rees [12]. The overall district is generally prosperous, as one would expect in Surrey, a county adjacent to the London conurbation and featuring a mix of suburbs, mid- and large size towns, and densely-wooded countryside with villages, hamlets, and military reservations with low population density. The red circle in Figure 2 indicates the study area, which is a mixed neighbourhood not far from the town centre. Note, however, that the study region contains an area classified as "constrained by circumstances" within a larger area of "typical traits" and "blue collar communities" (OAC). Although the wider borough has a higher than average ethnic minority composition, the sample area has a predominately white population which is younger than average, not only for the district but also for England as a whole (IMD 2010 [10]; ONS 2001 [11]). The area is close to the median level of deprivation for England as a whole but is one of the most deprived areas in the locality itself.

We now turn to a profile of crime and disorder in the area. In Figure 3, crime rates in 2009 per 1000 head of population show that the study area is in a fairly low crime area for the Borough, although there are two locations within it which do experience higher rates. Also, in Figure 3, the vulnerable localities index (VLI) [13] is displayed for the area. The VLI is a composite measure derived from both Census data and recorded crime data. It is a measure of community vulnerability and is used by government and official agencies to identify neighbourhoods that require priority attention from the police and local crime and disorder reduction partnerships (CDRP). Here we see that while most of the borough experiences low levels of vulnerability on this measure, the sample area does contain locations of higher vulnerability for the overall region (those areas that score more than 200 on the VLI). We will now turn to one of those areas which has both a higher crime rate and is officially regarded as being in need of priority attention.

Figure 4 focuses on individual crime events in the sample area and highlights the problems with such postcode located data. In the area defined as "constrained by circumstances" in the output area classifications, note that the three crime locations actually represent 36 recorded crimes which have been located at three postcode centroids. It is not clear from a centroid-based image that multiple crimes were actually attributed to several points. This illustrates one problem in attending only to the classic "etic" viewpoint. It is a problem of granularity. As we will see, methods directed to the emic dimension reveal the more nuanced view of the relationship of place to crime risk applied by people aware of the finegrained microhistory of the locale. It should also be noted that previous analysis [14] of a local Community Safety Survey conducted in 2004 for the Borough Council confirmed that one part of this ward had a bad reputation and was deemed by nonresidents to be a place to avoid. In fact, despite its reputation, $G^{* * *}$ Road has an active residents association and a website which lists "Twenty Great reasons for Living in the $P^{* * *}$ Croft \& $G^{* * *}$ Road Area".

So what was the local public's feeling about crime and disorder in their area? Did $G^{* * *}$ Road residents see it as a place in which they would rather not reside?

In the same 2004 Community Safety Survey, analysis (see Figure 5) indicated that "fear of being a victim of crime" was quite low down the concerns of the respondents, ranked at 15 th out of 18 in a list of neighbourhood problems. It was well below problems associated with traffic, parking, and vehicles 


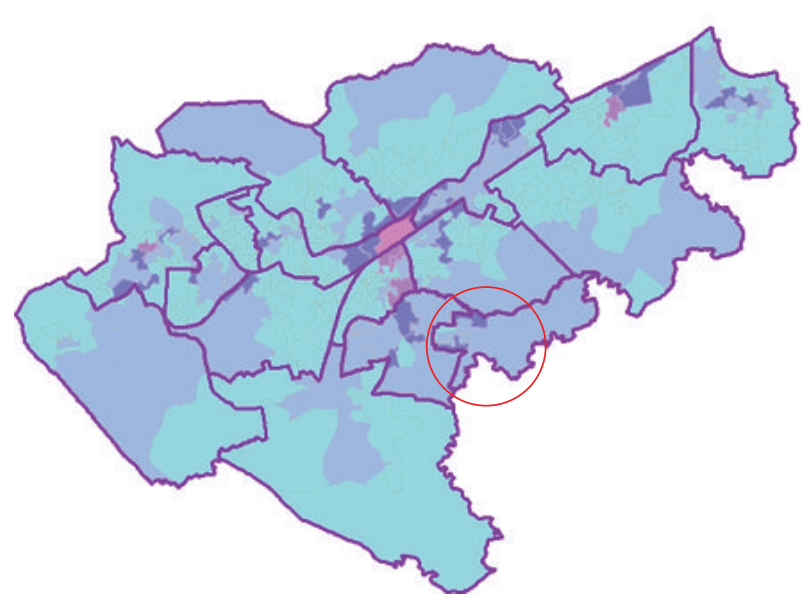

Total crime rates $2009 / 1000$ population rate 2009

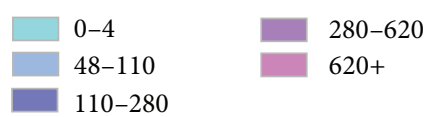

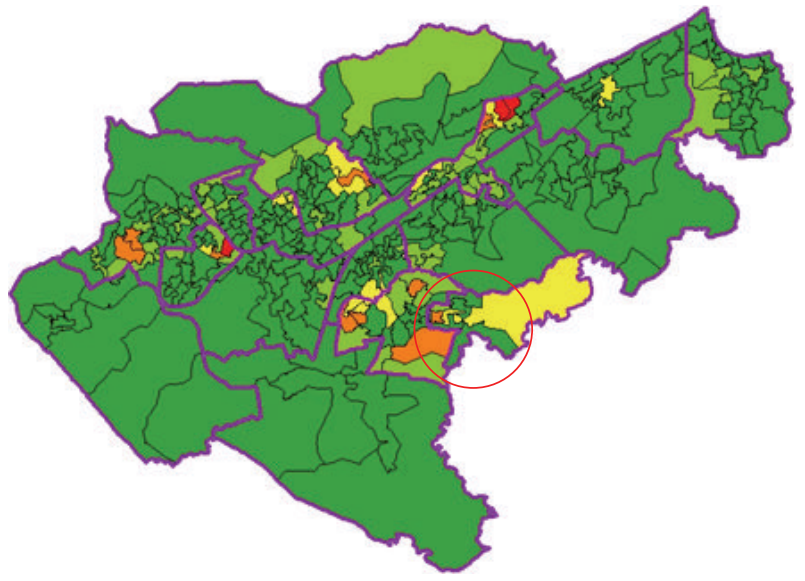

Vulnerable localities index 2009 VLINDEX200

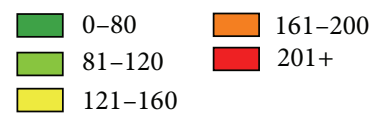

FIGURE 3: Recorded crime rates per 1000 population and the vulnerable localities index. Circle indicates sample area.

that feature as three of the six most highly rated problems for the area.

It is, of course, the multidimensional picture we get from combining methods that enables techniques of discovery. Thus, the quantitative and spatial analysis element gave a useful etic baseline against which to compare the primary data from the qualitative fieldwork procedures, to which we looked for insight into the emic dimension.

3.2. Fieldwork towards an Emic Perspective. The tracks and conversations of mobile interviews with local people, community representatives, and PCSOs were recorded while walking around a route chosen by them within the locality (participants were simply asked to take the researcher on a walk round notable places in their locale and to comment on why places were notable). In this demonstrator project we conducted six mobile interviews with residents, one with the local PCSO and two researcher-led community audits. The residents interviewed comprised four females aged between 30 and 40 and two older males, one aged between 50 and 60 and the other over 70 . All respondents had lived within the area for at least four years, and most for much longer, and had children, grandchildren or, in the case of the oldest male, great grandchildren. The PCSO interviewed lived outside the area. We called these "mobile interviews" but they are often also referred to as "walk-along" interviews. The unaccompanied environmental scans of the area were conducted using a smartphone running SurveyToGo software to log the instances, geographical position, and any artefacts of incivilities that were observed (e.g., abandoned cars) or of events that had taken place (e.g., marks on buildings from objects thrown at them). This methodology is based on the environmental scan techniques developed by Fielding et al.
[15] for Surrey Police as part of their "Reassurance Policing" programme, the forerunner of Neighbourhood Policing.

To give a sense of the mobile fieldwork, Figure 6 is a visual representation of the tracks of 7 mobile interviews and 2 community audit walks, with waypoints "flagged" for one interview in Google Earth [16]. Waypoints were convenient points at which the researcher accompanying the interview participant logged the coordinates on the GPS device to more easily synchronise the interview data with the track data during analysis. Integrating exact location with utterances in the mobile interview enabled more precise insights into why given locations elicited particular feelings or memories. Participants appeared to find being at the location a trigger to a fuller response, with higher affect (emotional salience) as well as more exact anecdotal detail when compared to response to similar items in a static interview format conducted in a meeting room. For analytic purposes, being able to visualise the location and specific route taken while coding the transcripts using CAQDAS software (such as MAXQDA and ATLAS-ti) provided an extra dimension and insight into meaning, especially for members of the research team who were not present during the interview. However, while one can easily synchronise the transcripts with the audio within the CAQDAS software to facilitate coding of the transcript (albeit in lapsed time, i.e., starting at time zero), synchronising the audio with the mapped route in real time proved more difficult. One can run the "time slider animation" within Google Earth to visualise the route taken, but while it is calibrated in real GMT time, it is very much speeded up. Thus, it is not possible to listen to the real-time audio at the same time. Synchronising tracks with audio in real time was possible with Open Street Map (OSM) [17], but then coding was not possible in this software, as it is a mapping application. Thus, to listen to all the talk in a given 


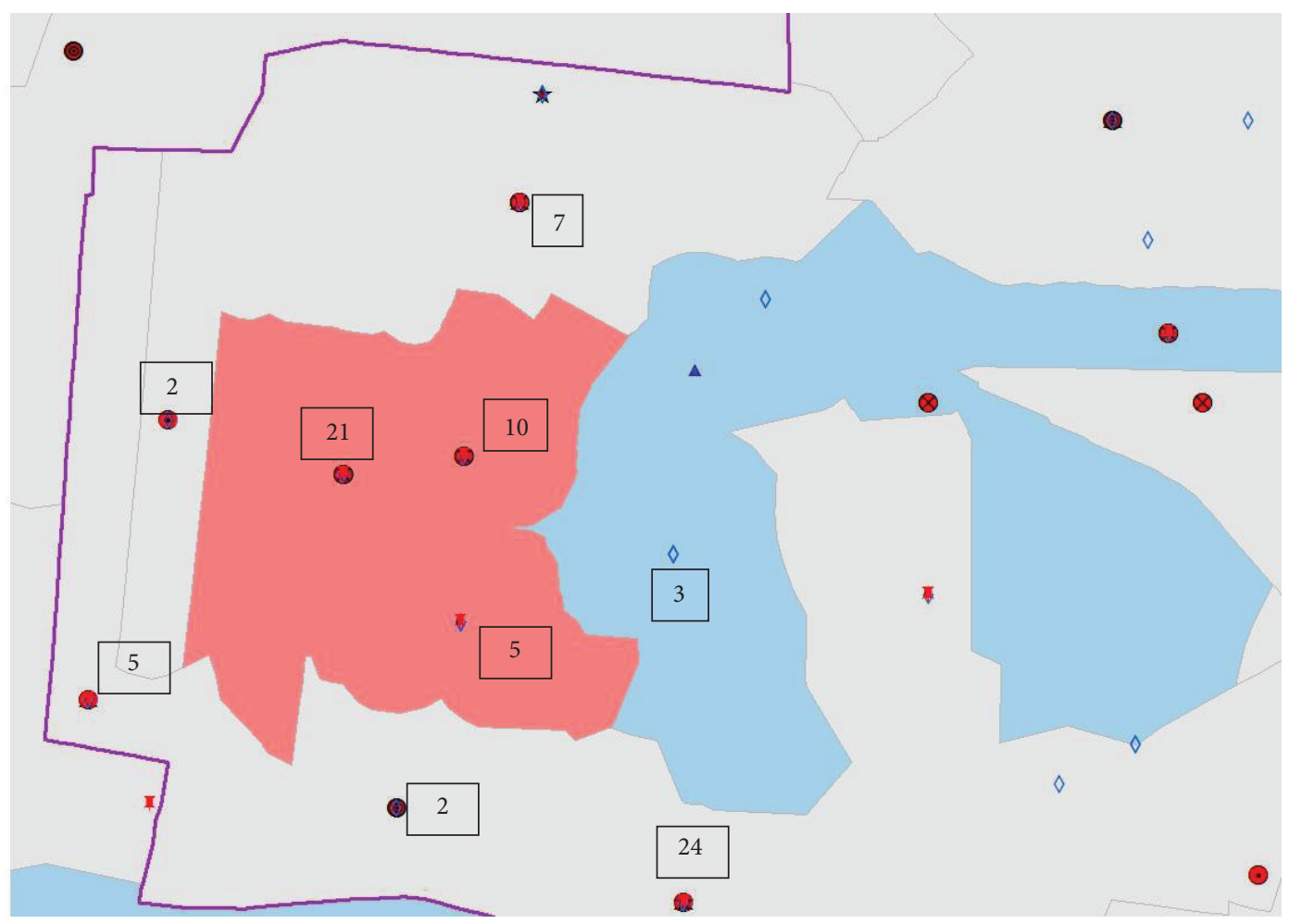

Total crime events in 2009 OFFENSER

- Burglary dwelling

- Burglary nondwelling

() Criminal damage vehicles

Q Criminal damage-dwelling

- Criminal damage-non-dwelling

Drug offenses

$\square$ Fraud and forgery

$\odot$ Other

+ Robbery

- Sexual offenses

$\diamond$ Theft and handling

I. Violence against person

FIGURE 4: Area classifications and crime event data. Numbers indicate crime events at postcode centroid.

area, one had to use Open Street Map in conjunction, but not in synchrony, with the CAQDAS software which was used for coding the data.

\section{Discussion}

4.1. Communities as Social Capital. Social capital theory [18] tells us that it is not only economic resources or their lack that affect fear of crime and experience of the reality of crime. While the wealthy can assuage their fear of crime and deter the reality of crime, with crime prevention measures such as gated communities and high tech security systems, the less well-off can secure themselves by resources of neighbourliness, collective action, and simply by knowing the area well. We are used to seeing high population turnover as a sign of an unstable, risky area but we do not so often explore how low population turnover provides deep local knowledge that can insulate people against crime by such things as knowing where not to be if one wants to avoid a given risk.

The "signal crimes" perspective applied by Innes and Fielding [19] in their work on the Surrey and Metropolitan Police experiments with reassurance policing and their evaluation of the Home Office programme of Neighbourhood Policing [20-22] encouraged us to focus on differences in knowledge resources held by users of a given space against a geographical frame of reference. A classic instance collected in the Neighbourhood Policing evaluation was of the varying levels of fear of crime relating to respondents' residential proximity to the scene of a vicious rape and murder. Innes and Fielding found that, in the immediate aftermath, those who lived in the same borough but who were reliant on the local media for information had a higher fear of similar victimisation than those who lived in the building where it had happened. Immediate neighbours were acquainted 


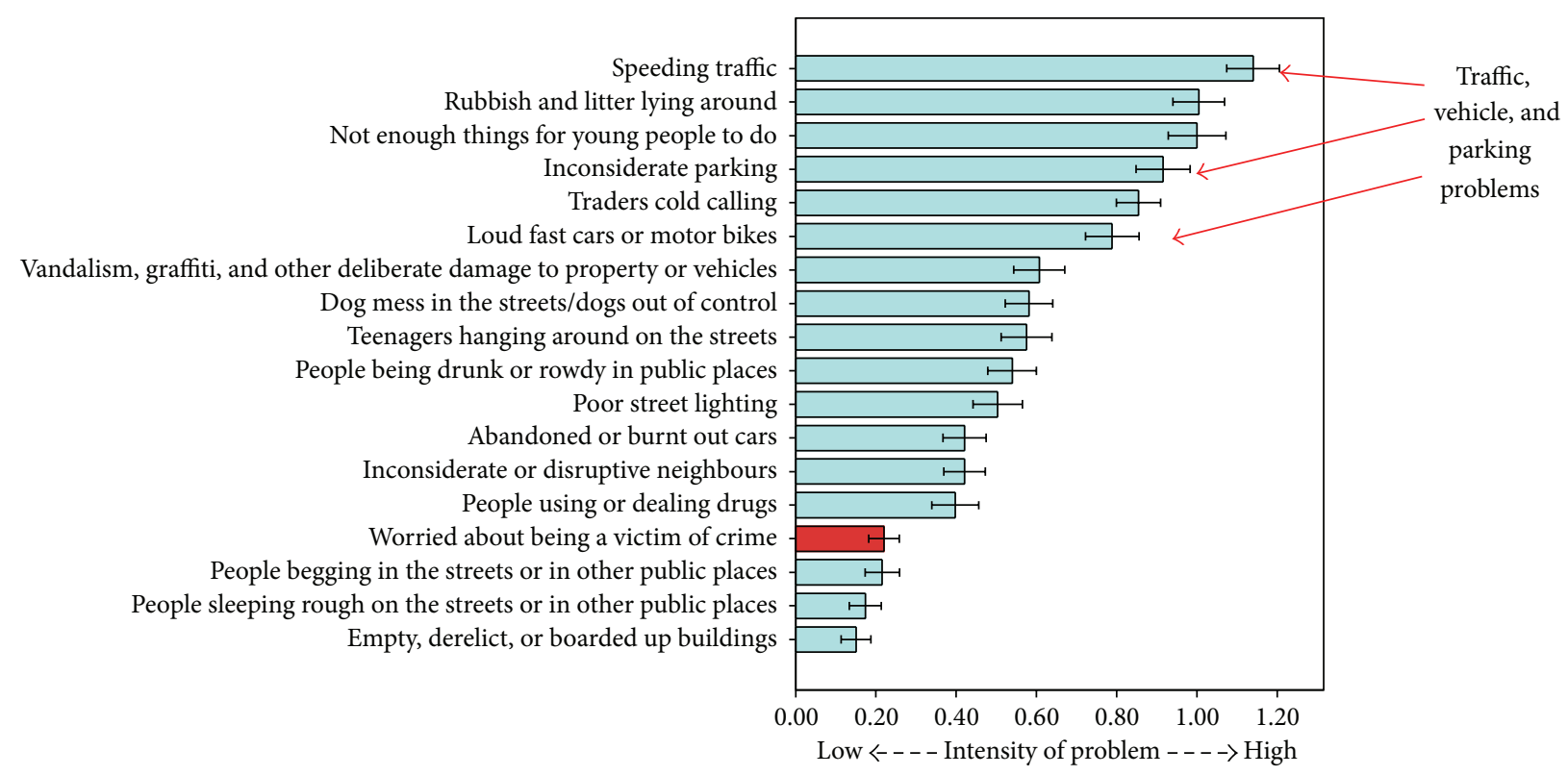

Errors bars: 95\% CI

FIgURE 5: Problems in the neighbourhood and worry about being a victim of crime.

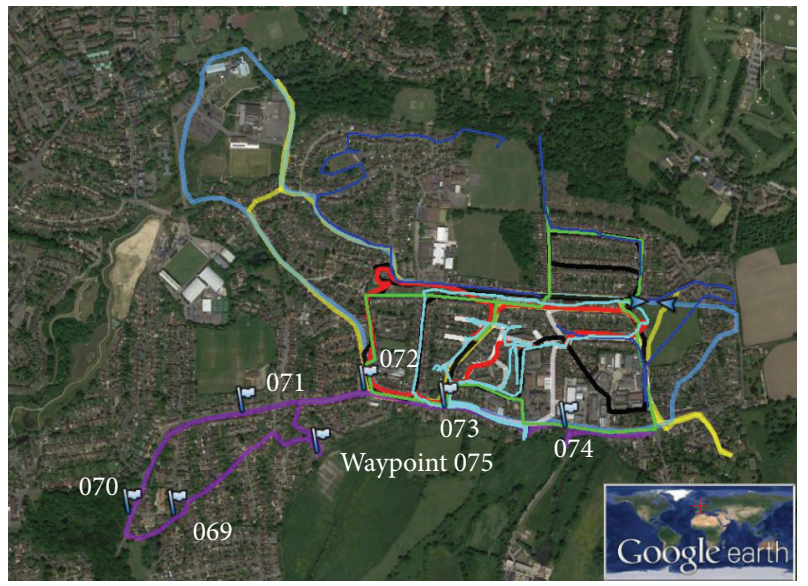

FIGURE 6: Mobile Interviews tracks in Google Earth. Source: Google Earth @2013 Infoterra Ltd \& Bluesky.

with the precise details of the incident and knew what had motivated it and that the motive ruled out anyone else being similarly victimised.

The crime and disorder reality of the fieldwork site involved in the present study was a great deal more humdrum than that, but it does give us some examples of similar knowledge resources in action.

One street within the study area had gained a bad reputation over many years and was mentioned by all but one of the respondents at some point during the walking interviews. One respondent who lived near this street, $G^{* * *}$ Road, said that

We've got $G^{* * *}$ Road, coming off $R^{* * *}$ Way, and for years and years it was nothing but trouble on this road, I mean really sort of heavy stuff, and these sort of things sort of stick in your mind a little bit, you know. And [locality] unfortunately had a bit of reputation for that. (Int 6 \#271-lives nearby)

Yet, those who live in the street have a more measured response and even an explanation for its bad reputation:

Oh! I mean we've had some bad trouble here over the years. I mean they used to put all the riff raff down here. Everybody that did not pay their rent anywhere else, they used to dump them down here. (Int 4 \#7-resident)

And the same resident said that

Well it has the worst reputation in this area, but actually it's not that bad. It's actually quite nice to live here. It's a good community. [...] I mean you'll find most people that are scared to come down $G^{* * *}$ Road are people that do not live there. They, they've just heard about it, and they won't even walk down it. (Int 4 \#326-resident)

And another resident explained that

I think what impresses me with this community is the fact that there's so many people that actually like the community and want to do things for it. (Int 5 \#352-resident)

Although milder in scale, these comments indicate a similar phenomenon to the rape example, around the more general theme of a street's reputation. Those living closest to the actual problems were able to isolate the specific locations in their minds and still see the positives around them. 
Note that the presentation of crime data on the police public website [23] goes against the grain of this approach. The practice of standardising the crime locations to the middle of the postcode to preserve privacy may well reinforce the reputational damage to the whole street.

In areas of the sort we researched, medium and major serious crime is rare, but incivilities such as shouting matches between neighbours, egg and stone throwing at houses, and the routine vandalism of plantings, gates, and signs gave parts of the area character that was reflected in expressions of real uneasiness and frustration on the part of our respondents. For the most part these were people who were active in the community and who seemed to go out of their way to find the positives in their community and its residents, so we would argue that the frustrations and fears they expressed would be all the more likely in others who were less active, less in the know, and more housebound.

Importantly for analysis, though, we collected examples of ways in which such individuals made their own accommodations to the circumstances in which they found themselves. Formal agencies were certainly part of the landscape through which individuals negotiated their way to their objectives, but individuals typecast the function of such agencies and seldom regarded them as flexible resources available to them or as a gateway to such resources. Instead, they sought to negotiate obstacles to their goals by taking direct, individual initiative. For instance, a woman with two school age children, who, following divorce, was no longer able to afford to live in the area of town in which she had grown up, confronted the problem of poor schooling in the district to which she had been obliged to move. She was concerned about the potential influence of local children with whom her own children may come in contact. Rather than seeking official interventions against the unruly children in her new neighbourhood, she resolved the problem by converting from one Christian denomination to another, gaining access for her children to a faith school with high standards. Also concerned about afterschool contact, she confined the play area of her children and regulated their use of bicycles.

4.2. The Role of Official Agencies. Having briefly profiled the community's informal social resources, we now turn to the role of official agencies. We customarily think of frontline agencies such as the police, the local authority, housing associations, social services, and the youth service as agencies unambiguously arrayed against crime and disorder. However, our research has sensitised us not only to the positive effects of interventions by these agencies but to the unintended criminogenic consequences of some of their policies and actions. These are attested by the comments from several of the respondents about the parking problems in the area. A typical example is expressed by one respondent:

\section{We only have got 2 visitor's parking, and because most people have more than one car there's always rows about parking. (Int 7 \#185)}

Another respondent goes on to mention a more serious consequence of the parking problems in the area:
We've got an old people's block... we're finding the ambulances having to take them across the grass in the stretchers to get, because they cannot park anywhere near it. So we're trying to get double yellow lines just in front of the door, ... stop the permanent parking right in front of the door. Because it is, definitely a risk issue, it's happened 3 times this year, we've had an ambulance not able to park there. (Int 2 \#426)

A local authority planning department that stipulates a limited number of parking spaces for a new housing development on the basis that use of the car is to be discouraged and people must be nudged to use public transport may produce a feel-good effect in town hall but is also highly likely to create tensions between the development's residents as they struggle over limited parking and trouble for pedestrians and emergency services with obstructed footpaths and verges.

One revealing example of the way in which the policies and decisions of formal agencies can have unintended criminogenic effects which require closely engaged local fieldwork to discover came to us as a direct result of the technologyenhanced methods of discovery we were using. The example concerns persistent antisocial behaviour at a particular new estate of mixed social and owner-occupier housing which came up in the interview with the PCSO while walking through the area:

... when I first took over the area, it was flaggedup as one of my specific projects. In the fact that we had antisocial behaviour there, there were children causing problems, or there was a perception that they were causing problems. So one of the first things we did was, we tried to identify some of the key stakeholders in the area, bearing in mind it's part-buy part-rent part-ownership. Now the people that owned their properties had their own residents' group, OK, which was great but there was a little bit of... alienation between the owners' residents group and the part-buy part-rent people.

So what we went about doing was, in partnership, was to set up a Neighbourhood Watch Scheme,... the idea was that everybody in the estate could be involved in it. And that's what we've done, and it seems to work quite well. (Int 1 \#9-15)

To explore the reported levels of antisocial behaviour in the area, we first turned to the mapped images and explored the physical location of the area in Google Earth. We sought to further explore another issue mentioned by five of the seven respondents while they were walking through the same area-that the new estate used to be the site of an old factory:

\section{And then there was a great big factory, [anon], the [anon] factory in front of it. But on the back of the houses there was just this open abandoned bit of land that belonged to the council, and they sold it to build all these houses. (Int 2 \#170)}

Using historical Google Earth imagery, we were able to explore the area in 2004 and again in 2010. It is thus 
straightforward to see how the location of interest has changed over recent time. The two images seen in Figure 7 show how an old factory site has been developed as a new housing estate. The waste ground mentioned in Interview 2, which was sold for new housing, is seen outlined in the image on the left.

One of our respondents, a resident of the new estate thus created, told us how she had been troubled by youths throwing eggs at the houses on the estate. Another respondent, in the course of bemoaning the obtrusive three-storey block, latterly built here for social housing on the periphery of the estate (see Google Street View Image in Figure 8), reminisced about how her children used to play in the waste ground beside the old factory. A third spoke about the excessive height of the fence erected around the new development, possibly intended to help the sales of the owner-occupier houses located further within the boundaries of the estate:

When this was first built, this estate, it had a much higher fence. But they had to take it down because it contravened planning permission. And so it was, I think, six/seven foot before and they had to drop it down to the level it is now. Erm, quite a lot of bad feeling they did ... [...] the established estate in $R^{* * *}$ and $G^{* * *}$ Road and that, there was a lot of resentment. Erm and we have had cases of unsocial behaviour of people coming over from the other estate into our estate and just running amok, vandalising the fences, throwing bins around and just generally being oiks. (Int 7 \#175)

Looking at these images, these accounts suggest to us that the egg-throwing reported by residents may be an expression of resentment at a lost amenity, reinforced by the exclusionary nature of the high fences. In a full-scale study this hypothesis would, of course, be subject of a "member check" procedure. Now that the fences had been lowered, removing the perceived barrier between this new estate and the old established estates in the neighbourhood, it would seem to have reduced the unintended barrier which, according to our fieldwork respondents, incited neighbourhood rivalries leading to antisocial behaviour.

... there was concern that there was a solid fence with no gates in it, separating that community from the village community, and got it changed, so there's gates. OK there's problems, there's a bit of vandalism here and there and a bit of hassle, but at the end of the day [...], there's no barrier. (Int 5 \#58)

Ironically, the victims of this antisocial behaviour appeared to be the social-housing tenants who were most similar in sociodemographic background to the assumed perpetrators implicated by the victims.

To the urban planner, the waste ground adjacent to an old factory may merely be disused, but to local people it may be a site with a valued use but one that is invisible to officialdom, a case analogous to the "urban gardens" that local residents had created on waste ground in Knigge and Cope's [24] study of the social geography of community integration in the "rustbelt" city of Buffalo, New York. The high fences, perhaps designed to protect the residents on the new estate, actually provoked the opposite reaction.

To explore the impact of the PCSO's interventions in setting up a neighbourhood watch scheme and the local resident's perceptions of improvements in the area once the high fence was removed, we explored the local crime trends in the area since our fieldwork was completed. Using the http://www.police.uk website we collated crime event data for the specific new estate area (by defining the boundaries of the estate by "drawing your own area" within the website; see box in Figure 9) over a period of time since the interview with the PCSO in October 2009. From this data we found that the number of crime events in this small estate area totalled 51 in 2011 compared to 30 crime events in 2012, indicative of a fall in reported crime over this two-year period.

However, plotting quarterly crime in this area over the same period in comparison with the wider borough area of Old Woking (see Figure 10) does show that reported crime is falling more generally and is indeed following national trends in this respect [25]. The technique used in this demonstrator project would, of course, be useful in disentangling local and wider regional/national contextual effects.

A further indication of the locale's microhistory that may colour attitudes and condition antisocial behaviour in the area relates to another nearby development. Close to the location shown in Figure 7 is an unusual development site, land set aside between the wars for a bypass that was never built (see the grassy open space on the bottom left to top right diagonal in Figure 11).

The community that lived on either side of this strip had a mixed reputation as asserted by the PCSO while walking through this area:

But there's a little bit of a divide, I've got to be honest, and this is only what residents have told $u s$, there's a little bit of a divide between $R^{* * *}$ Way ... they say that this end of $R^{* * *}$ Way is the nice part and the top end is not such a nice part.

[...]

I do not know why, but you know, the houses this end seem to be more, shall we say, presentable from the outside, than the houses further up the top end, near the rec. (Int 1 \#285-289)

This central strip of land appears to have been a central feature of the communities around it with stories of informal cricket and football games, and as can be seen in this Google Earth image, there are lots of free parking spaces. During the fieldwork period, development went ahead and this green "stripe" was being built upon (the near-completed development is now visible in Google Street View), despite a long campaign against the developers. On the basis of the suggestive evidence presented above, we might speculate that the first occupants of the new houses being built there could encounter antisocial behaviour problems, especially in view of the shape of the site. The area appeared to function as both 
2004

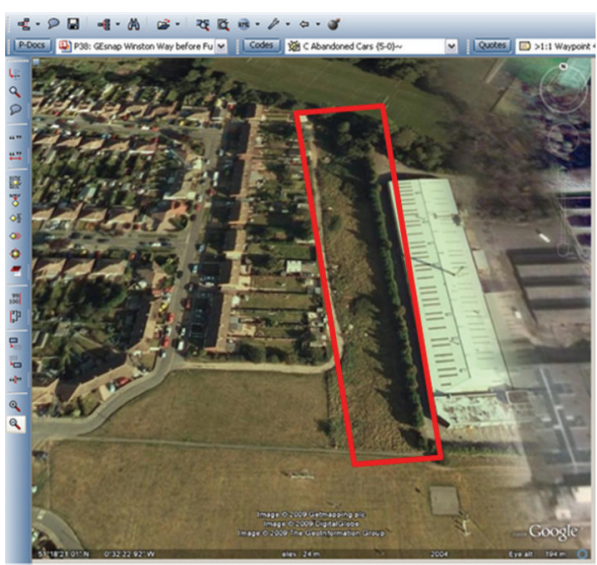

2010

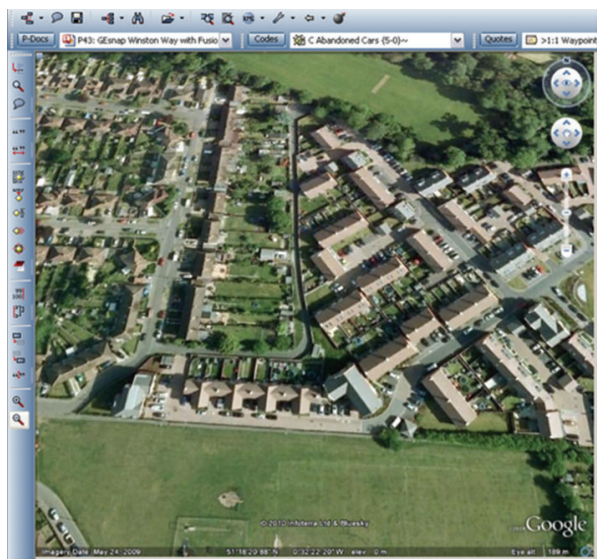

FIGURE 7: Loss of amenity space-Google Earth images compared within ATLAS.ti v6. Source: Google Earth: (2004 image) Image @2009 Getmapping plc; Image (2009 DigitalGlobe; Image @2009 The GeoInformation. Group (2010 image) (02010 Infoterra Ltd \& Bluesky.

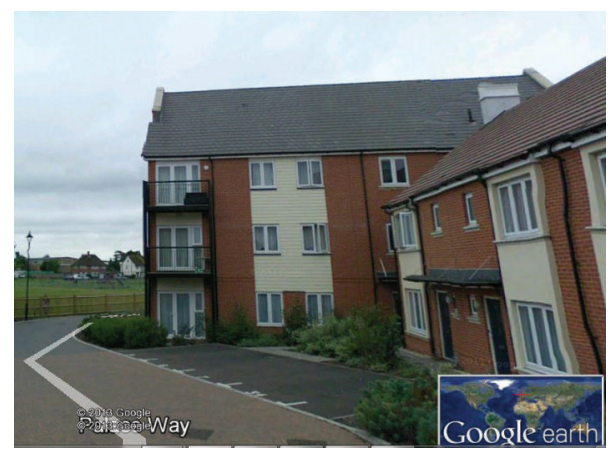

FIGURE 8: Google Street View image of social housing block on periphery of new estate. Source: Google Earth Street View (c) Google 2013.

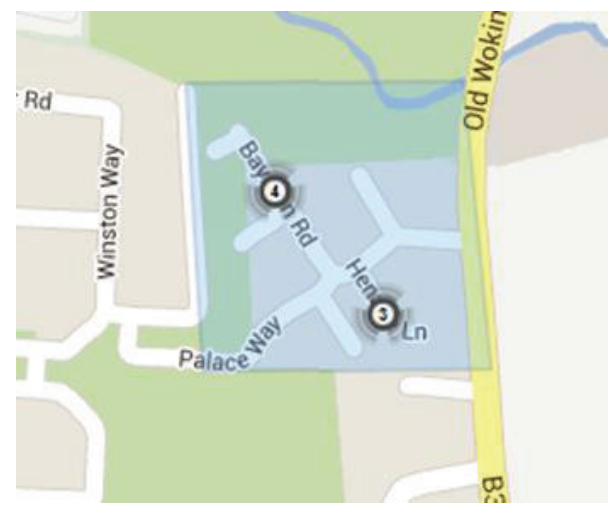

FIGURE 9: Box drawn to define new estate boundaries showing crime events for a selected month. Source: http://www.police.uk.

an informal boundary and an uncontested pressure valve for informal uses such as impromptu sports and play and overflow parking. Its useful but unofficial amenity may have helped reduce local tensions of a kind so regular as often to be dismissed as background "noise," a function lost due to

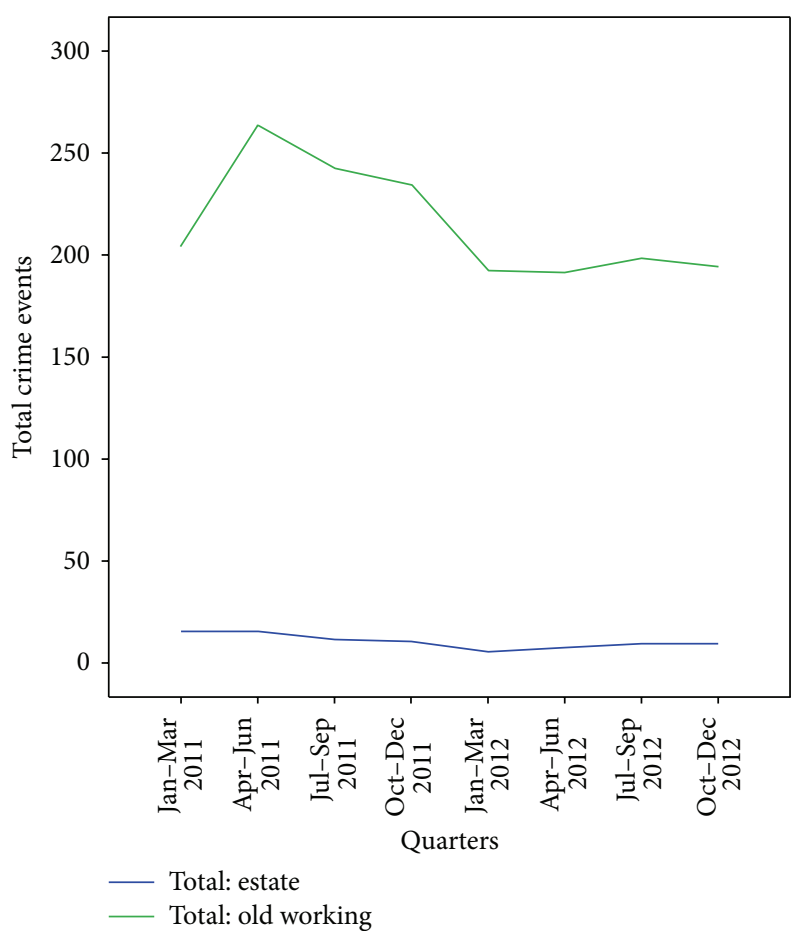

FIGURE 10: Total recorded crimes on the new estate in comparison with the wider local area. Source: http://www.police.uk.

the new housing development. To inform such hypotheses we needed both the "hard" or objective information about the physical topography and built environment of the area over time and the testimony about activities in the area provided by the mobile interviews.

\section{Conclusion}

We began the discussion in this paper with a distinction between emic and etic approaches, arguing that information from both is necessary to get a holistic picture and that 


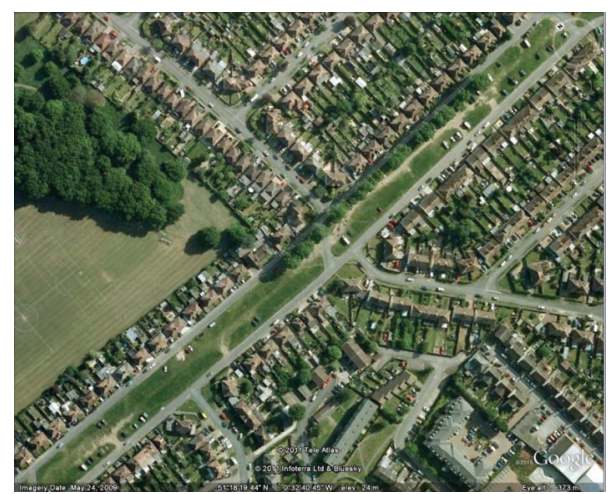

FIGURE 11: Future development site in Google Earth. Source: Google Earth: (2011 Tele Atlas: (C2011 Infoterra \& Bluesky.

the crime risk and community safety field is dominated by work using an etic approach. That approach offers an external perspective from outside the phenomenon, and its focus on structures and regularities gives it an affinity for quantitative methods. It answers questions about perceived risk and safety by offering findings on the lines of "this is a place where older/disabled people are objectively more vulnerable." The emic approach gives an insider's viewpoint, looking at the issue from a participant's perspective. It helps us answer questions like "why do some people feel more vulnerable in this place than others?" From a law enforcement and criminal justice priority-setting perspective, we need to be able to answer both kinds of questions, so this is not a case for the superiority of one method or heuristic over another but for understanding their interaction.

While we would support what is now the fairly commonplace view that mixed methods offer a more holistic picture [26], we would highlight that new research technologies cut across the familiar methods debates. For instance, the qualitative software we used to organise the data and support the coding and analysis process itself supports mixed methods because it has a suite of features enabling content analysis-type quantification of features in the field data; it supports Boolean retrievals that enable systematic formal analysis of the data using selective retrieval strategies, and for more complex statistical work it can export data to statistical software. Bearing in mind the examples represented in Figures 7 and 11, one of the most promising current technical developments is the georeferencing of qualitative software and its interoperability with Google Earth, Streetview, and other map and location image providers. This begins to provide criminological researchers with some of the power that geographers have long enjoyed with software like ArcGIS.

We anticipate that these technical developments, including increasing interoperability between different IT tools, may bring about a revival of some of the elegant work on the criminal area associated with the classic urban ecology studies of figures such as Morris [27] and Bottoms et al. $[28,29]$. As one of us wrote in a book on qualitative software [30], with new research technologies, we can do more but we also have more to do. In the domain of community crime risk assessment it may help us better understand why the wellintentioned policies of local agencies are often confounded, why people in relatively risky areas and with the wherewithal to relocate still choose to stay put, and ultimately why the crime "map" is not the territory.

The more nuanced understanding of the perceived risk of crime based on combining the emic and etic dimensions in a mixed methods research design facilitated by new research technologies carries implications for research on the fear of crime more generally. The stream of research engendered by applications of Putnam's conceptualisation of social capital [18] from the 1990s onwards has resulted in a clearer and fuller understanding of the factors in the physical and social environment that weigh on the public's fear of crime in jurisdictions such as the US, the UK, and other "mature" democracies. While it has never been more true that the fear of crime involves a complex set of responses to the physical, socioeconomic, and cultural environment, we now have an empirical base that allows us to be a good deal more certain and discriminating in weighing the relative influence of the factors in play and the way that they interact.

The extent of the fear of crime literature and the robustness of the studies comprising it make it possible and legitimate to apply the techniques of secondary analysis, such as those of the systematic review, to the literature reporting primary studies. When this is done, some clear regularities in the results of primary studies emerge. These regularities are consistent with the broad lines of analysis, and the methodological techniques used, in the research reported in the present paper. Thus, Lorenc et al. [31] inspected 18 crime, health, and social science databases for UK studies presenting data on fear of crime and the environment. Applying the Hawker et al. framework [32], they identified 40 studies meeting the criteria for inclusion in a systematic review. While the review identified several factors in the physical environment having impact on the public's fear of crime, such as visibility and signs of neglect (as per the "broken windows hypothesis" of Wilson and Kelling [33]), Lorenc et al. (page 496) found that "factors in the local social environment appear to be more important as drivers of fear of crime." The factors prominently include social networks and familiarity with the locale.

The original focus of the Lorenc et al. review was on the built (physical) environment but early in their work this was widened to include the social environment. This revealed interesting enculturated thinking and mechanisms behind thoughts on the built environment; for example, those measures such as locks, fencing, and secure entry systems reduce fear when installed in private space but their equivalent, such as shutters and security gates, can raise fear in public space. There was an issue of balance, where some security measures were needed to instil reassurance but an excess of security measures in the home was seen as "unwelcoming and depressing." Sociocultural factors were also at work in the finding that while strong, well-placed lighting boosted confidence in urban settings, dwellers in the countryside felt safe in their domain without expecting or feeling the need for heavy lighting. People also balanced the natural surveillance afforded by clear sight lines and uncluttered street design against feelings of being under observation and were reassured by "a sense of 'openness' in 
the environment" [31, page 500]. Yet wholly deserted areas widely induced fear. The established fear-inducing elements of the physical environment, the kinds of decay, vandalism, and neglect encapsulated in the "broken windows" idea, registered widely in the studies reviewed, but, importantly, reaction to these was mediated by knowledge of, and familiarity with an area. Familiarity inspired a feeling of safety despite the presence of "objective" fear-inducing features in the physical environment. Moreover, the public explicitly recognised that outsiders may feel fearful in a locale in which residents and regular visitors felt confident and unthreatened.

Such findings are highly consistent with those reported in the present study and, indeed, quotations extracted from the underlying studies and presented in Lorenc et al's review are expressed in closely similar terms to some of those we presented earlier. The underlying cognition supporting this is clearly indicated by Lorenc et al.: "much of the protective effect of familiarity has to do with having strong social networks locally" [31, page 500]. This consistent finding is, of course, welcome, but in terms of ongoing research, we would note the "granularity" of the findings from our fieldwork, where subtle differences in confidence and perceived risk were expressed in relation to small movements around the streetscape and features imperceptible to the fieldworker until pointed out by community members.

Several of the studies captured in the Lorenc et al. systematic review suggest respondents relating to a broader geographical frame of reference than the neighbourhood level in our own study, an issue we regard as worth fuller exploration, as it has methodological as well as substantive implications. Lorenc et al. also identify an intriguing aspect of the established gender difference in relating to areas of perceived risk or safety, that of “"vicarious' fear" [31, page 501] expressed by the parents or partners of females. As Lorenc et al. note, there are parallels in work on the perceptions of ethnic and sexual minorities, to which we might add those who are subject to "hate crime" on the basis of their appearance. We would regard systematic comparison of crime fear and risk perception amongst these groups as a promising avenue for further research, given that some have only latterly been legally recognised as likely to suffer distinctive experience of criminal victimisation.

We would certainly endorse Lorenc et al.s assessment that "aspects of the physical built environment are clearly relevant to fear to some extent, but fear often relates more directly to the environment's social meanings than its physical form" [31, page 501]. This opens the door to an approach that acknowledges both the generic factors that reliably induce crime fear in a population and factors that mediate the fear response in analytically suggestive ways, such as the idea that some variations in crime fear may reflect conflict between different stances towards the normative standards that frame contemporary constructions of deviance and morality.

\section{Acknowledgments}

The research discussed in this paper was conducted under the aegis of the Qualitative Innovations in CAQDAS (QUIC) node of the National Centre for Research Methods (NCRM) and was supported by the UK Economic and Social Research Council (Grant no. RES-576-25-0002).

\section{References}

[1] M. Innes, "Signal crimes and signal disorders: notes on deviance as communicative action," British Journal of Sociology, vol. 55, no. 3, pp. 335-355, 2004.

[2] N. Fielding and C. A. Cisneros-Puebla, "CAQDAS-GIS convergence: toward a new integrated mixed method research practice?" Journal of Mixed Methods Research, vol. 3, no. 4, pp. 349370, 2009.

[3] J. Spiers, "New perspectives on vulnerability using emic and etic approaches," Journal of Advanced Nursing, vol. 31, no. 3, pp. 715$721,2000$.

[4] J. Fielding, "Environmental injustice or just the lie of the land: an investigation of the socio-economic class of those at risk from flooding in England and Wales," Sociological Research Online, vol. 12, no. 4, 2007, http://www.socresonline.org.uk/12/ 4/4.html.

[5] Dooblo Ltd, "Survey to go software," http://www.dooblo.net/ stgi/surveytogo.aspx.

[6] Scientific Software, "ATLAS-ti: the qualitative and data analysis research software," http://www.atlasti.com/.

[7] Verbi GmbH, "MAXQDA, qualitative data analysis software," http://www.maxqda.com/.

[8] N. G. Fielding and J. L. Fielding, Linking Data: The Articulation of Qualitative and Quantitative Methods in Social Research, Sage, Beverly Hills, Calif, USA, 1986.

[9] Department of Health Home Office, Working together under the Children Act 1989: A Guide to Arrangements for Inter-Agency CoOperation for the Protection of Children from Abuse, Stationery Office Books, London, UK, 1991.

[10] ONS, "Neighbourhood statistics," http://neighbourhood.statistics.gov.uk/dissemination/.

[11] IMD, "Indices of multiple deprivation," 2010, http://www.communities.gov.uk/communities/research/indicesdeprivation/ deprivation $10 /$.

[12] D. Vickers and P. Rees, "Creating the UK national statistics 2001 output area classification," Journal of the Royal Statistical Society A, vol. 170, no. 2, pp. 379-403, 2007.

[13] S. Chainey, "Identifying priority neighbourhoods using the vulnerable localities index," Policing, vol. 2, pp. 196-209, 2008.

[14] SSMR, "Safer woking partnership," Survey Final Report, Surrey Social \& Market Research, University of Surrey, Guildford, UK, 2004.

[15] N. Fielding, M. Innes, and J. Fielding, Reassurance Policing and the Visual Environmental Crime Audit in Surrey Police: A Report, University of Surrey, Guildford, UK, 2002.

[16] Google Earth Inc, "Google earth," http://earth.google.com/.

[17] Open Street Map Foundation, "Open street map (OSM)," http://www.openstreetmap.org/.

[18] R. D. Putnam, "Bowling alone: America's declining social capital," Journal of Democracy, vol. 6, pp. 65-78, 1995.

[19] M. Innes and N. Fielding, "From community to communicative policing: "signal crimes" and the problem of public reassurance," Sociological Research Online, vol. 7, no. 2, 2002, http://www.socresonline.org.uk/7/2/innes.html.

[20] Home Office, Neighbourhood Policing: Your Police, Your Community, Our Commitment, Home Office, London, UK, 2005. 
[21] M. Innes, S. Hayden, T. Lowe, H. Mackenzie, C. Roberts, and L. Twyman, Signal Crimes and Reassurance Policing Volumes 1 and 2, University of Surrey, Guildford, UK, 2004.

[22] M. Innes, S. Hayden, T. Lowe, and C. Roberts, Signal Crimes and Reassurance Policing Volume 3, University of Surrey, Guildford, UK, 2005.

[23] Police UK, “Police UK," http://www.police.uk.

[24] L. Knigge and M. Cope, "Grounded visualization: integrating the analysis of qualitative and quantitative data through grounded theory and visualization," Environment and Planning A, vol. 38, no. 11, pp. 2021-2037, 2006.

[25] Economic Policy Centre, “UK crime statistics," http://www.ukcrimestats.com/National_Picture/.

[26] J. W. Creswell, Research Design: Qualitative, Quantitative, and Mixed Methods Approaches, Sage, London, UK, 2009.

[27] T. Morris, The Criminal Area: A Study in Social Ecology, Routledge \& Kegan Paul, London, UK, 1957.

[28] J. Baldwin, A. E. Bottoms, and M. A. Walker, The Urban Criminal: A Study in Sheffield, Tavistock Publications, London, IK, 1976.

[29] A. Bottoms and P. Wiles, "Explanations of crime and place," in Crime, Policing, and Place: Essays in Environmental Criminology, D. J. Evans and N. R. Fyfe, Eds., pp. 11-35, Routledge, London, UK, 1992.

[30] N. Fielding and R. Lee, Computer Analysis and Qualitative Research, Sage, London, UK, 1998.

[31] T. Lorenc, M. Petticrew, M. Whitehead et al., "Fear of crime and the environment: systematic review of UK qualitative evidence," BMC Public Health, vol. 13, pp. 496-503, 2013.

[32] S. Hawker, S. Payne, C. Kerr, M. Hardey, and J. Powell, "Appraising the evidence: reviewing disparate data systematically," Qualitative Health Research, vol. 12, no. 9, pp. 1284-1299, 2002.

[33] J. Wilson and G. Kelling, "The police and neighborhood safety: broken windows," Atlantic Monthly, vol. 127, pp. 29-38, 1982. 

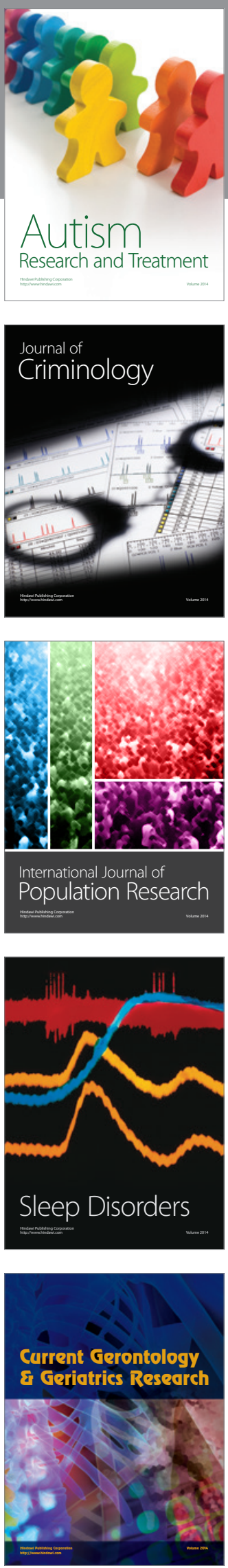
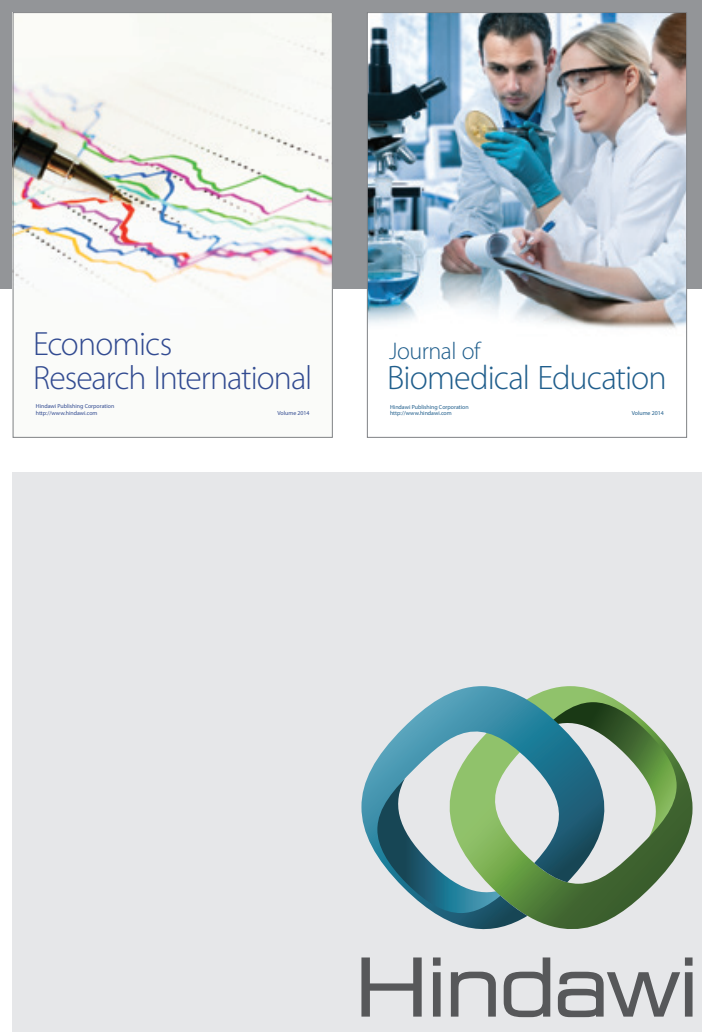

Submit your manuscripts at

http://www.hindawi.com
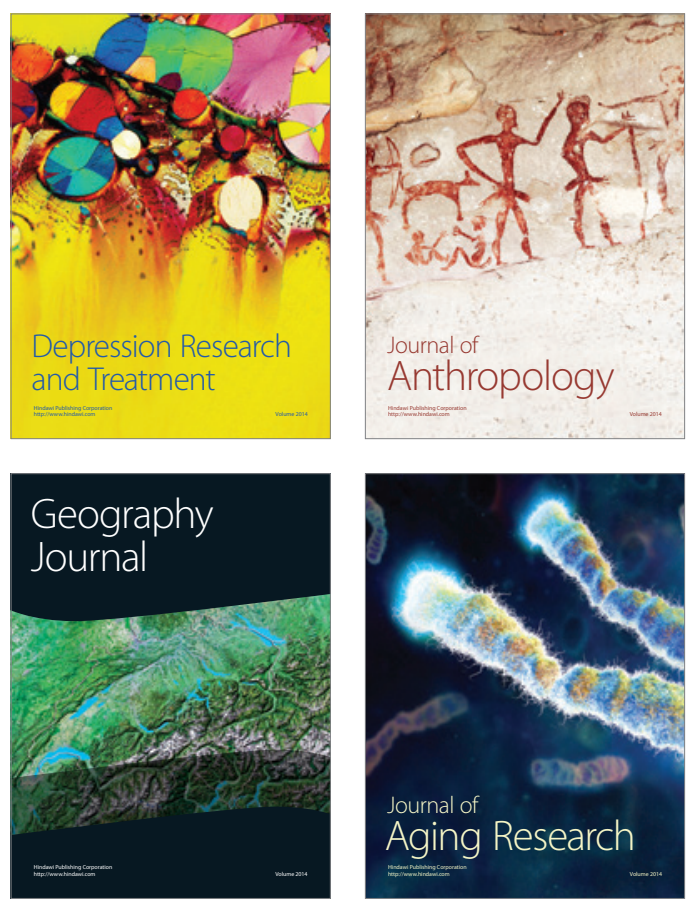
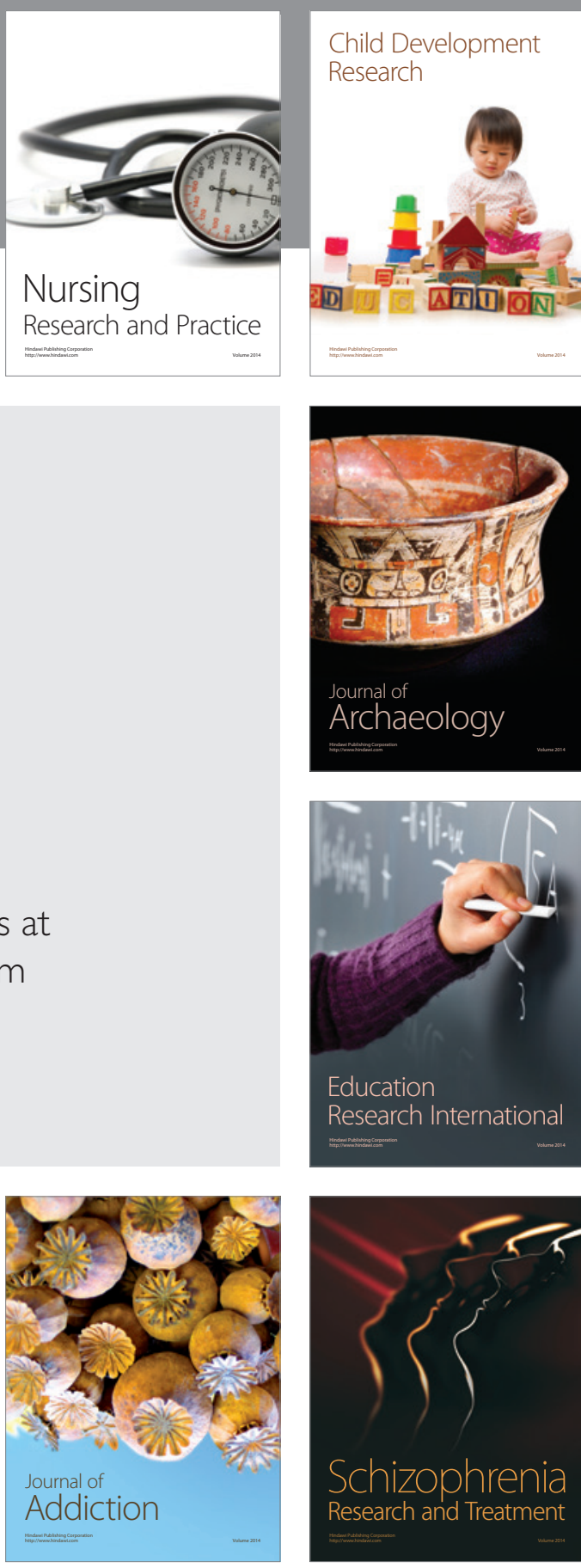

(D)
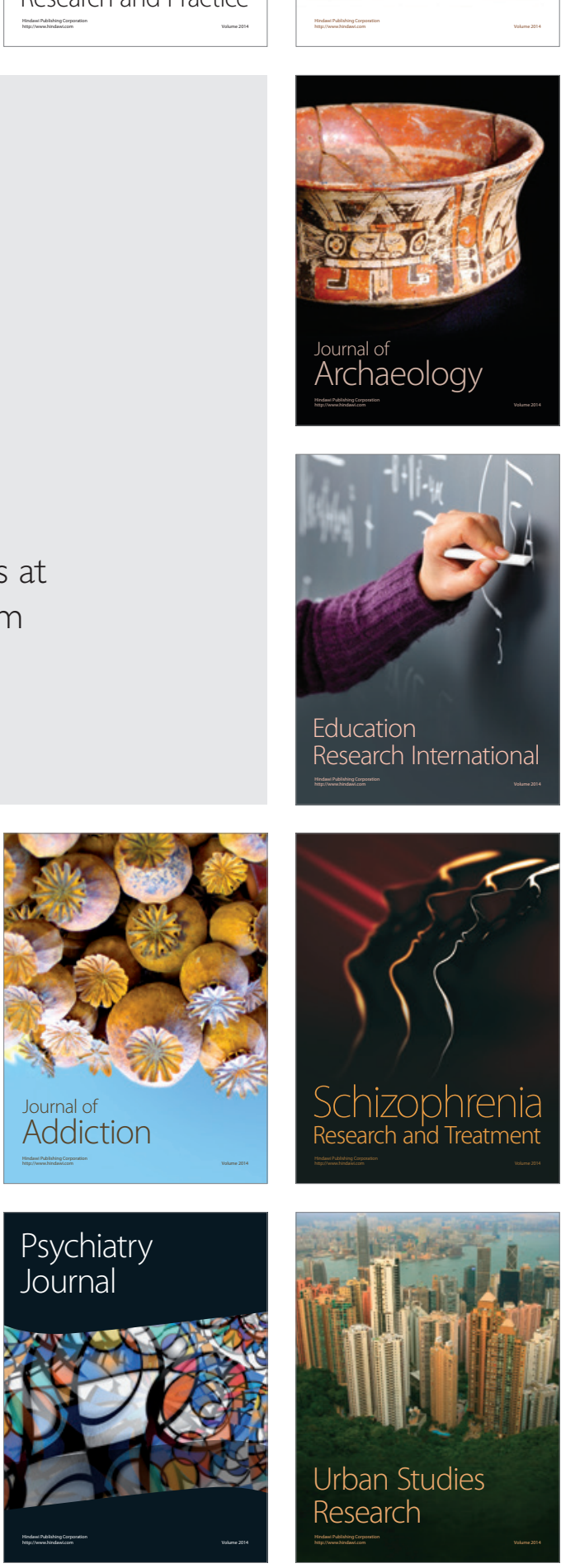